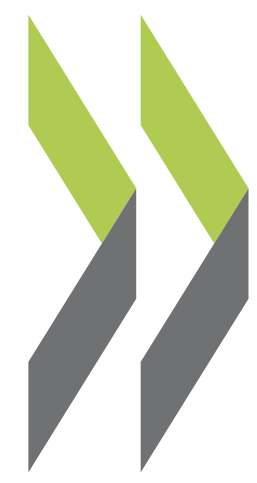

CELE Exchange, Centre for Effective Learning Environments $2011 / 08$

\title{
Have all the Costs \\ of Closing a School Been Considered?
}

\section{Michael Lytton}

https://dx.doi.org/10.1787/5kg5c8bwqs31-en 


\section{Have all the costs of closing a school been considered?}

By Michael Lytton, ${ }^{*}$ Lytton Consulting, United States

Many schools around the world are struggling in the face of reduced funding and fluctuating enrolments. Often, the solution to this unhappy equation is quite simply to shut down facilities. But when all the costs of closing a school are considered - financial, material and human-implementing this policy calls for caution.

\section{THE PROBLEM FACING AMERICAN SCHOOLS TODAY}

Public school administrators in the United States have a tough job at the best of times. Enrolment ebbs and flows, funding fluctuates and the curriculum constantly evolves. Billions of dollars of public assets are managed under the watchful eyes of the community, and facility managers cope with a massive backlog of maintenance and repairs after prolonged underinvestment in public infrastructure.

Stakeholders are calling for national levels of educational performance to improve, while school systems are having to cope with the most severe downturn of the economy in decades. Districts across the country are struggling to balance their budgets in the face of decreased local revenue, cuts to state funding, and the disappearance of federal stimulus packages.

\section{TWO FACTORS WHICH TRIGGER CLOSURES}

At the same time, enrolments - always a moving target, each year producing capacity surpluses or deficits on a regional, local and school-by-school basis - have become even less predictable. Although the US Department of Education projects that the nation's overall public school population will add 10 million students by $2030,{ }^{1}$ some districts are currently growing faster than historical trends would predict, while others are contracting overall or experiencing large disparities in utilisation rates between schools.

The utilisation rate corresponds to the ratio of enrolled students to a school's capacity. If every classroom is fully occupied (in an ideal world only), the utilisation rate would be $100 \%$. In reality some schools in a district will be overcrowded, while others are under-utilised, hence the disparities between schools. The extent and duration of under-utilisation are critical factors in determining if a school remains operationally viable, and in the absence of standardised thresholds, these factors are highly contentious. School district budget managers argue that "under-utilised schools", as they define them, are no longer cost-effective and should be closed. While the assumptions in such arguments are complex, it should nevertheless be noted that the lingering fiscal effects of the recession embolden budget managers to contend that schools must be cost effective, however that term is defined.

*Michael Lytton is a consulting school facilities planner with two decades experience in public education.

1. U.S. Department of Education, Office of Public Affairs (2000), Growing Pains: The Challenge of Overcrowded Schools is Here to Stay, Washington, D.C., www.ed.gov/pubs/bbecho00/. 
At the same time, the U.S. Department of Education's Elementary and Secondary Education Act (also known as the No Child Left Behind Act), has various mechanisms to measure the educational performance of students. If specific annual targets for the entire school are not met, a series of interventions are mandated under the Act. Repeated failure to meet educational performance targets can trigger termination of the instructional programme at a school, and possibly replacement of administrators and teachers. Thus, educational performance is typically the second argument put forth by school district officials for closing a school altogether.

\section{The impact on schools}

School district administrators describe their fiscal problems in crisis terms, and respond to immediate budget shortfalls by reducing operating costs, of which by far the largest proportion (up to $80 \%$ ) is personnel. This means laying off teachers, eliminating central office jobs and seeking concessions from unions. And where such actions are insufficient to bridge budget gaps, instructional programmes and student transportation are cut.

Increasingly, staff reductions are accompanied by school closures. Citing under-utilised classrooms, district officials argue that they can no longer afford to operate schools with excess capacity. A further justification might be that a building has become obsolete and beyond economical repair or upgrading. The quick-fix option is to close the school: a process euphemistically termed "shuttering." Severely under-utilised schools are consolidated; closed facilities are either mothballed, leased to non-public education providers, adapted to non-instructional purposes, sold, or demolished.

The current spate of closures raises a number of issues, most of which reflect uncertainties that complicate the task of decision makers who ponder whether shuttering facilities is the right way to address a (hopefully temporary) budget challenge. These variables can be framed as questions:

- Are fiscal problems related only to current economic conditions or are they possibly a culmination of previous financial missteps?

- Does the school system face a long-term fiscal imbalance? If so, how long and how severe?

- Might current enrolment declines reverse? If so, when and by how much?

- What is the threshold and duration of excess capacity that determines when a school is financially insupportable?

- What criteria are used to establish that a building is obsolete and beyond repair or modernisation? Note: age alone is not sufficient.

- What options are available in lieu of closing a school? Do they include cost savings through modernisation, or potential revenue generation from the school?

- Have all the economic costs and community impacts of closing a school been identified and formally evaluated by decision makers?

In the absence of definitive answers to these questions, three points should be kept in mind: i) with adequate maintenance, buildings can be useful almost indefinitely, ii) life-cycle planning for schools needs to accommodate fluctuations in enrolment, evolving curricula and changing roles in the community over time; and iii) modernisation must be a strategic plank in education reform efforts because upgraded schools are better places for teaching and learning. 


\section{THE FULL COSTS OF SCHOOL CLOSURE}

The consequences impact on both schools and the community, and include: one-time expenditures to make an existing school ready to accommodate additional students; lost funding if students leave the public education system; diminished education outcomes; and multiple impacts levied on a community when a neighbourhood school is shuttered.

One-time expenditures. The financial costs of closing schools are often underestimated, starting with a miscalculation of one-time expenditures for moving students, staff and supplies. These can entail modifications of existing schools to accommodate students and staff that have been displaced from elsewhere. Adding or enlarging science and computer labs, reconfiguring and restocking libraries as well as renovating administration areas are typical required improvements. Health and safety codes might also be applied, mandating additional washrooms, more parking, or handicap access improvements. It is not unusual for such one-time expenses to exceed USD 1 million per school.

Student departure from public schools. Another potential financial cost is the loss of per-pupil funding if students opt out of public schools altogether. Eliminating neighbourhood schools and/or leasing shuttered schools to non-public agencies are actions that, if not well thought out, may encourage students to exit the public school system, only exacerbating the fiscal problems in struggling districts. In California for example, one school district predicted savings of USD 700000 through consolidation, but ended up losing some USD 2.4 million in funding as hundreds of students pulled out of the public system within months. ${ }^{2}$

Indirect and community impacts. In addition to direct economic costs of closing schools, there are numerous indirect costs affecting both education and the community. For instance, studies indicate that schools located outside a neighbourhood reduce the extra-curricular activities of students, as well as the active involvement of parents. Enlarging class sizes, eliminating instructional programmes, truncating full-day kindergarten and early childhood programmes and providing fewer adult parenting classes are all examples of potential results of closed neighbourhood schools that will likely have a negative impact on educational performance.

Schools are also key indicators of community vitality and sustainability. They influence where families choose to live, property values and tax revenues, and the pace and location of residential and commercial development. Neighbourhood schools play multiple roles, not only providing facilities for teaching and learning, but offering resources to help meet the social, recreational, health and personal needs of the community. This is especially true in small or rural locations where schools are among the few public facilities that can provide meeting space, serve as recreation centres, and offer adult education. Many communities rely on schools to house health clinics, day care centres, after-school social programmes, and so forth.

Shuttering a school can therefore have widespread and lingering consequences for a neighbourhood, often falling disproportionately on poorer communities. Areas without good schools do not readily attract young families, and closing schools can decrease nearby property values. Communities already afflicted by lost jobs and homes will be shaken further by the closing of a neighbourhood school, particularly if the decision-making process has been acrimonious. Fallout from strained community relations, such as eroded confidence in decision making or withdrawn support for municipal bond measures, can affect

2. Carlson, C. and Hernandez, M. (2011), "Officials say school closures can save millions: but as students leave, so does funding. Is it worth it?", The Ventura County Star, 16 March, www.vcstar.com/news/2008/mar/16/no-headline---na 1 fcclosures16/. 
school boards for years.

Neighbourhood schools are also instrumental in efforts to increase physical activity and reverse the epidemic of childhood obesity. James Sallis, a professor at San Diego State University and the Director of the Robert Wood Johnson Foundation's "Active Living Research" programme has this to say: "Children need safe places to play, and every neighbourhood has a school with outdoor recreation facilities and sometimes indoor facilities. However, low-income neighbourhoods often do not have parks or recreation centres, so schools often are the only places for safe physical activity. Closing schools in low-income neighbourhoods takes away the only opportunity for active play for children at high risk of obesity who need these resources the most." ${ }^{\prime 3}$

\section{CONCLUSIONS}

These examples of indirect and community impacts of closing public schools, or turning them over to non-public education providers, raises a larger question about divestment of public assets in general. The results of privatisation of public infrastructure have been decidedly mixed, and it is with some foreboding that we see a politically driven movement in the United States to encourage private alternatives to public education. It is also unclear if abandoning capital assets that have been publicly funded is not in some sense a violation of the pact between citizens and school boards.

Nevertheless, district leadership that is considering closing schools must make difficult decisions. Uncertainties and ramifications far beyond the immediate budget issue make the task enormously difficult. All costs and indirect consequences must be identified and carefully evaluated. A full range of feasible economies and cost-avoidance options must also be analysed and ranked. And the community needs to be engaged as collaborative stakeholders in the decision-making process.

Good examples are being developed and tested in school districts as disparate as Vancouver BC, Cleveland $\mathrm{OH}$, Portland $\mathrm{OR}$ and Charlotte-Mecklenburg NC, to name a few. But common to all is a thoughtful approach that recognises and respects the importance of schools in a community - not only as work and learning places, but also as vibrant centres of recreation, public health and social interaction. In these districts closing a school may be the right decision, but it should always be a last resort.

For more information, contact:

Michael Lytton, M.Plan, LEED AP

4458 42nd Street

San Diego

California 92116

United States

E-mail:mlytton@m/c-schoolfacilities.com

3. Sallis J., San Diego State University (2011), personal e-mail communication with the author. 


\section{ORGANISATION FOR ECONOMIC CO-OPERATION AND DEVELOPMENT}

The OECD is a unique forum where governments work together to address the economic, social and environmental challenges of globalisation. The OECD is also at the forefront of efforts to understand and to help governments respond to new developments and concerns, such as corporate governance, the information economy and the challenges of an ageing population. The Organisation provides a setting where governments can compare policy experiences, seek answers to common problems, identify good practice and work to co-ordinate domestic and international policies.

The OECD member countries are: Australia, Austria, Belgium, Canada, Chile, the Czech Republic, Denmark, Estonia, Finland, France, Germany, Greece, Hungary, Iceland, Ireland, Israel, Italy, Japan, Korea, Luxembourg, Mexico, the Netherlands, New Zealand, Norway, Poland, Portugal, the Slovak Republic, Slovenia, Spain, Sweden, Switzerland, Turkey, the United Kingdom and the United States. The European Commission takes part in the work of the OECD.

OECD Publishing disseminates widely the results of the Organisation's statistics gathering and research on economic, social and environmental issues, as well as the conventions, guidelines and standards agreed by its members.

This work is published on the responsibility of the Secretary-General of the OECD. The opinions expressed and arguments employed herein do not necessarily reflect the official views of the Organisation or of the governments of its member countries. 